\title{
ASTROTURF: INTEREST GROUP LOBBYING AND CORPORATE STRATEGY
}

\author{
THOMAS P. LYON \\ Michigan Business School \\ University of Michigan \\ Ann Arbor, MI 48109 \\ tlyon@umich.edu \\ JOHN W. MAXWELL \\ Kelley School of Business \\ Indiana University \\ Bloomington, IN 47405 \\ jwmax@indiana.edu
}

We study three corporate nonmarket strategies designed to influence the lobbying behavior of other special interest groups: (1) astroturf, in which the firm covertly subsidizes a group with similar views to lobby when it normally would not; (2) the bear hug, in which the firm overtly pays a group to alter its lobbying activities; and (3) self-regulation, in which the firm voluntarily limits the potential social harm from its activities. All three strategies reduce the informativeness of lobbying, and all reduce the payoff of the public decisionmaker. We show that the decision-maker would benefit by requiring the public disclosure of funds spent on astroturf lobbying but that the availability of alternative influence strategies limits the impact of such a policy.

\section{INTRODUCTION}

The role of interest groups in politics has held a long-standing fascination for political economists. In the 1780s, James Madison famously warned of the power of "factions" in The Federalist, while nearly 200 years later Mancur Olson and George Stigler elevated the study

We would like to thank two anonymous referees and participants in a number of seminars for their helpful comments, including the 2002 Strategy and the Business Environment Conference at Stanford University, Cambridge University, Katholieke University of Leuven, the University of Bonn, the 21st Rutgers Workshop on Public Utility Regulation, the Second World Congress of the Association of Environmental and Resource Economists, University of Victoria, Resources for the Future, Indiana University, and Harvard University.

(C) 2004 Blackwell Publishing, 350 Main Street, Malden, MA 02148, USA, and 9600 Garsington Road, Oxford OX4 2DQ, UK.

Journal of Economics \& Management Strategy, Volume 13, Number 4, Winter 2004, 561-597 
of interest group politics to an important subfield within economics. ${ }^{1}$ Pioneering theoretical work in the Chicago School tradition treated interest group "pressure" as a production function, smooth and twice continuously differentiable. ${ }^{2}$ In this framework, interest groups compete to apply more pressure in a game where rival pressure inputs are strategic complements. More recently, theorists have been opening up the black box of political pressure to focus more explicitly on specific strategies such as campaign contributions or lobbying. ${ }^{3}$

Several recent papers shed new light on the role of lobbying in conveying "soft," i.e., unverifiable, information to public decision-makers. ${ }^{4}$ In these models, interest groups may be able credibly to transmit soft information about the state of the world if their preferences do not diverge too greatly from those of the decision-maker. This recent work, however, typically does not distinguish firms from other special interest groups. We argue that in many lobbying situations, firms cannot convey unverifiable information credibly because their payoffs depend only on the policy imposed by decision-makers and not on the underlying state of the world. In the case of local environmental issues, for example, the relevant state of the world is the environmental damage done by a particular pollutant, which often is unknown to policymakers. However, environmental regulations often require firms to use the "best available control technology," the cost of which is independent of the state of the world. Does this mean the firm is impotent in such situations, or are there other strategies it can employ to influence the information decision-makers receive? What impact might these alternative strategies have on public decision-making? Existing models shed no light on these questions, since they do not distinguish between the firm and other interests involved in transmitting soft information to decision-makers.

In this paper, we present a formal model of lobbying as a means of transmitting unverifiable information and clearly distinguish the firm from other special interest groups. We show that while the firm is not

1. Olson (1965) elaborates a rational choice model of interest group action, while Stigler (1971) applies this approach to the study of regulation specifically.

2. Key early papers include those of Peltzman (1976) and Becker (1983). For an analysis of self-regulation that builds on this literature, see Maxwell et al. (2000).

3. For example, Lupia and McCubbins (1994) and de Figueiredo et al. (1999) study how administrative procedures can be designed to optimize the flow of information to politicians, and Baron (2001) develops a model in which activists attempt to influence corporate strategy via the threat of consumer boycotts. Kollman (1998) studies the motivations and strategy behind lobbying behavior based on detailed interviews with 90 interest group leaders. Grossman and Helpman (2001) provide an excellent introduction to the recent theoretical literature on interest group politics.

4. See, for example, Lohmann (1993) and Krishna and Morgan (2001). These models, which build on the seminal work of Crawford and Sobel (1982), must be distinguished from models of the provision of "hard," verifiable information, as analyzed in papers such as Milgrom and Roberts (1986). 
a credible source of such information, it nevertheless can influence the lobbying behavior of other interest groups through a variety of strategies. The decision-maker initially is uncertain of the state of the world and desires full information so that he can match the stringency of policy to the severity of the state of the world. The firm, however, has incentives to manipulate the flow of information to the decisionmaker. We explore a series of corporate strategies that impede the flow of information to the decision-maker, show that the decision-maker is harmed by these strategies, and identify public policies that hinder the firm's ability to engage in them.

Most prominent among the strategies we consider is the funding of astroturf lobbying, a term coined by Lloyd Bentsen, long-time senator from Texas, to describe the artificial grassroots campaigns created by public relations (PR) firms (Stauber and Rampton, 1995, p. 79). One such firm is Davies Communications, whose advertising says, "Traditional lobbying is no longer enough. Today numbers count. To win in the hearing room, you must reach out to create grassroots support. To outnumber your opponents, call the leading grassroots public affairs communications specialists" (Stauber and Rampton, 1995, p. 90). Davies explains how his firm generates a "grassroots" letter-writing campaign through the use of telephone banks:

We get them on the phone, and while we're on the phone we say 'Will you write a letter?' 'Sure.' 'Do you have time to write it?' 'Not really.' 'Could we write the letter for you? I could put you on the phone right now with someone who could help you write a letter. Just hold, we have a writer standing by' ... If they're close by we hand-deliver it. We hand-write it out on 'little kitty cat stationery' if it's a little old lady. If it's a business we take it over to be photocopied on someone's letterhead. [We] use different stamps, different envelopes. Getting a pile of personalized letters that have a different look to them is what you want to strive for (Stauber and Rampton, 1995, p. 89-91).

One example of astroturf lobbying is the group People for the West! (PFW!) which characterizes itself as "a grassroots campaign supporting western communities." In 1992, 96\% of the group's funding came from corporate sponsors such as NERCO Minerals, Cyprus Minerals, Chevron, and Hecla Mining, who have strong interests in maintaining the General Mining Act of 1872 that allows them to acquire and to mine public lands at a cost of $\$ 5$ per acre. The chair of PFW!, Bob Quick, is the national director of state legislative affairs for Asarco, a mining 
company. ${ }^{5}$ Another example is the Consumer Alliance, a Michiganbased nonprofit that opposes laws to lower the price of prescription drugs to Medicaid participants and other low-income citizens. A public relations firm called Bonner \& Associates-funded by the Pharmaceutical Research and Manufacturers of America (PhRMA) - uses Consumer Alliance letterhead to solicit signatures in support of its positions. ${ }^{6}$

Astroturf lobbying relies on the covert nature of corporate sponsorship in achieving its effectiveness, and Congress is well aware of the possibility that some apparent grassroots lobbying campaigns may have been manufactured by large corporations. Indeed, as we discuss further in section 3 of the paper, Senator Carl Levin has sponsored legislation that would require the disclosure of corporate expenditures on such lobbying. The language on astroturf lobbying was stripped from the bill that ultimately was passed, however, leaving this particular lobbying technique obscured from public view. We argue that while disclosure would be socially beneficial, it would not be a panacea, due to the availability of alternative corporate strategies that in many cases can accomplish the same outcomes as astroturf lobbying.

We coin the term bear hug to refer to a second corporate strategy of embracing one's opposition through overt payments designed to alter their lobbying behavior. This undermines the opposition's ability to transmit its information through costly signaling. For example, DeSimone and Popoff (2000) point out that "it is also important to recognize that there can be a disparity of resources and information between business stakeholder groups that makes trust difficult to develop. This may sometimes require action to redress the balance. Since the BrentSpar incident-when opposition prevented Shell from disposing of a large oil storage platform at sea-the company has made space available for environmental groups to explain their point of view in educational and other materials that it has prepared" (p. 165).

In this example, Shell is subsidizing the communication efforts of environmental groups. The bear hug strategy also can involve paying interest groups not to communicate on certain issues. Several examples of such a strategy, according to Huberty (2003), come from Jesse Jackson's "Wall Street Project," which encourages large corporations to hire more minority employees, do more business with minority-owned firms, and place more minorities on their boards of directors. For instance, the Telecommunications Act of 1996 mandated certain minority set-asides, and Jackson appointed himself the task of overseeing whether large telecoms firms were doing enough to promote minority businesses. His

5. For further details, see Sanchez (1996).

6. For more details, see Craig (2002). 
threats to campaign against the proposed merger of SBC and Ameritech induced the two firms to give $\$ 500,000$ to Jackson's nonprofit Citizenship Education Fund. Afterward, Huberty (2003) reports, "Jackson overcame his concerns and praised the companies' commitment to diversity." Other corporations that have been induced through similar means to contribute to Jackson's organization include AT\&T, Viacom, GTE, Bell Atlantic, Verizon, Texaco, Kentucky Fried Chicken (KFC), Burger King, 7-Eleven, Coors, and Coca-Cola.?

The third strategy we examine, self-regulation, is quite different from the other two strategies in that it involves real changes in company operations designed to reduce the risks of social harm. For example, a paper company might choose to install a totally chlorine-free manufacturing process to eliminate the risk of emitting organochlorines into a body of water. If these actions are substantive enough, interest groups may decide that the further gains from lobbying are not enough to justify the costs, and they may eschew participation in the political process. The literature has examined environmental self-regulation from a variety of perspectives-but typically within the context of models with complete information. ${ }^{8}$ In the present paper, however, the decision-maker has incomplete information, which implies a heretofore unrecognized effect of self-regulation: it may stem the flow of information to the decisionmaker that would have allowed him to tailor the stringency of policy to the severity of the state of the world.

The remainder of the paper is organized as follows. Section 2 presents a simple model of the lobbying process. Section 3 studies astroturf lobbying, while Section 4 considers the bear hug. Section 5 addresses the effects of self-regulation, and Section 6 discusses extensions of our model to a setting with multiple interest groups. Section 7 concludes.

\section{A Simple MOdel of LobBying}

Our basic model of lobbying has three players: a government decisionmaker (DM), a special interest group (SIG), and a firm. ${ }^{9}$ As we will show, the firm's objective function is such that it cannot play a direct role

7. Huberty (2003) based his article on a book by Kenneth Timmerman titled Shakedown: Exposing the Real Jesse Jackson (Regnery Publishing, 2002).

8. For an introduction to this literature, see Lyon and Maxwell (forthcoming).

9. The model builds on the work of Potters and van Winden (1992). We have chosen to use a very simple underlying model and to eschew extensions such as those pursued by Lohmann (1993) in which the DM is uncertain about the SIG's bias and uses the extent of political turnout to infer the state of the world (although we do discuss the possibility of multiple SIGs in section 6). Grossman and Helpman (2001, ch. 5) provides a nice survey of these and other extensions to the basic model. For our purposes, though, these extensions would complicate matters without adding much additional insight. 
effectively in the lobbying process, though it may be able to influence the process through payments to the SIG or through self-regulation. We assume the existence of a proposal that affects the firm and requires the approval of the decision-maker, who may impose a variety of requirements on its passage to ensure that it is socially beneficial. The proposal might be an application for planning approval of a new manufacturing facility, in which case the DM may require that the manufacturer install certain emissions control systems as a condition of operation. In a legislative context, the proposal might call for amendment of the General Mining Act of 1872, in which case the DM might require the use of auctions to allocate mining rights on public lands, ensuring that the fiscal impact of the act is minimized. Alternatively, the proposal might be aimed at health care reform, in which case the DM might require state Medicaid programs to negotiate the lowest possible prices from pharmaceutical manufacturers. In each case, the proposal before the DM gives the affected firms a powerful incentive to attempt to influence the policy process.

For ease of presentation we couch our discussion in the context of a decision-maker's choice of stringency for a local planning permit to build a local manufacturing facility, though our results apply much more generally..$^{10}$ The construction of a manufacturing plant may have social effects through a variety of mechanisms: e.g., it may create jobs in the local community; it may affect the environmental quality of the surrounding community; and it may affect the health and safety of that community. These effects can be summarized by a variable $\theta \in \Re$, which represents the true state of the world. For simplicity, we will assume that the state of the world captures the net adverse social impact of the project and can be either "low" or "high," so $\theta \in\left\{\theta_{L}, \theta_{H}\right\}$.

The DM chooses a policy $p$ that indicates the stringency of the regulatory response to the proposed project. The DM is assumed to care about his or her constituency, perhaps because of reelection concerns. The DM's preferences are represented by $G=-(p-\theta)^{2}$, which implies

10. It is important to note that the modeling of the decision-maker as a unitary actor does not limit its applicability to the planning context. Other authors, such as Lohmann (1993), have used unitary-actor models to represent a political leader who responds to the preferences of the median voter. We will discuss our model's implications for the legislative context as appropriate later.

11. An alternative modeling approach would be to assume a continuous probability distribution over a compact set of states, as in the papers by Crawford and Sobel (1982) and Krishna and Morgan (2001). These papers show that equilibria in such settings typically involve the partitioning of the state space into a finite number of regions, with the informed party able to send only crude signals to the uninformed party regarding the region in which the state lies. Our formulation captures the key qualitative feature of these models with simpler mathematical machinery by allowing for only two states. This allows us to focus more sharply on the alternative corporate strategies that are our main interest here. 
that the DM attempts to match the policy precisely to the state of the world. If the project is likely to have a highly adverse social impact on the local community, then the DM would favor setting a more stringent regulatory policy. Setting a policy that is higher than the true state is undesirable for the DM, because, for example, doing so might bring unnecessary economic hardship to the firm, which in turn may affect employment negatively in the local community. Setting too low a stringency also is undesirable for the DM, since community environmental, health, and safety conditions may be affected adversely. The DM's prior belief is that either state of the world is equally likely. ${ }^{12}$ Without further information, the DM's best policy decision is to

$$
\max _{p} \frac{1}{2}\left[-\left(p-\theta_{L}\right)^{2}\right]+\frac{1}{2}\left[-\left(p-\theta_{H}\right)^{2}\right] \text {. }
$$

Consequently, under conditions of uncertainty the DM's optimal decision is to set a moderately stringent policy of $p=\left(\theta_{L}+\theta_{H}\right) / 2$ with $E(G)=-\left(\theta_{H}-\theta_{L}\right)^{2} / 4$. We refer to a policy set at this level as the average policy.

The SIG is assumed to know the true state of the world. ${ }^{13}$ The SIG's preferences are given by $U=-(p-\theta-\delta)^{2}-l$, where $\delta$ represents the divergence between the SIG's preferences and those of the DM and where $l$ represents the cost to the SIG of lobbying the DM. Given this specification, the SIG always prefers a higher (lower) level of the policy $p$ than does the DM when $\delta$ is positive (negative). We refer to $\delta$ as the SIG's bias. The general form of the SIG's utility function captures the assumption that the SIG cares about both the project's social and economic effects on the local community. That is to say, even a positivebiased SIG may prefer a less stringent policy to a more stringent policy if the true state of the world is low enough. Note also that the lobbying cost $l$ can be interpreted as a proxy for the trade-offs the SIG must make in allocating its resources between lobbying and other valuable activities.

The location of manufacturing plants often is plagued by opposition from local residents who proclaim that the plant can be built-but "not in my backyard." While this may be a purely political phenomenon in some cases, in others it may reflect local knowledge of community preferences over the impacts of the project. In any event, it is natural to assume $\delta>0$ in this situation, and we use this assumption in laying

12. We could relax this assumption easily without changing the qualitative nature of our results, but we do not believe the additional notation would generate any new insights.

13. This may reflect technical knowledge, e.g., regarding groundwater flow in regions of karst topography, or social knowledge, e.g., regarding local community preferences. We also could allow the SIG to have imperfect information about the state without changing our results qualitatively. 
out the basic structure of the model. We begin our analysis with the case where $l=0$, i.e., the (positive-biased) SIG knows the true state of the world and can lobby costlessly (i.e., report the state to) the DM. We examine the SIG's incentives to report the true state of the world when the DM believes the SIG's announcement. Since the SIG always prefers a higher level of policy than the DM, it naturally has no incentive to misreport when the state is $\theta=\theta_{H}$. Misreporting may be desirable, however, if $\theta=\theta_{L}$. In this case, the SIG misreports, i.e., reports $\theta_{H}$, if its utility of obtaining $\theta_{H}$ in the low state exceeds its utility from reporting truthfully, that is, if

$-\left(\theta_{H}-\theta_{L}-\delta\right)^{2}>-\left(\theta_{L}-\theta_{L}-\delta\right)^{2}$.

Thus, when $\theta=\theta_{L}$, the SIG misreports if

$\delta>\left(\theta_{H}-\theta_{L}\right) / 2$.

Consider a case where condition (1) holds. This implies that the SIG has a large degree of bias or, alternatively, that the high and low states are relatively close together. In this case, the SIG always will report that $\theta=\theta_{H}$, regardless of the actual state of the world. Assuming the DM knows $\delta, \theta_{L}$, and $\theta_{H}$, she will recognize the SIG's incentives and hence will not update her prior based on the SIG's report. Thus, the DM sets $p=\left(\theta_{L}+\theta_{H}\right) / 2$. If condition (1) fails to hold, then the SIG will report truthfully, and the DM will use the SIG's report to set a policy of $\theta_{L}$ in the low state and of $\theta_{H}$ in the high state. ${ }^{14}$

When condition (1) holds, the SIG cannot report truthfully if $l=0$, but it may be able to do so if lobbying is costly. Because the SIG is biased toward high levels of policy, it is concerned particularly about the possibility that the DM sets $p=\theta_{L}$ when the state is actually $\theta_{H}$. Thus, the SIG is motivated strongly to incur the cost of lobbying when the state is $\theta_{H}$ but may not find it worthwhile when $\theta=\theta_{L}$. Under certain conditions, which we explain following, there exists a sequential equilibrium ${ }^{15}$ (henceforth, an "equilibrium") in which the SIG only lobbies when $\theta=\theta_{H}$. In the equilibrium, the DM holds the belief that if the SIG lobbies then indeed $\theta=\theta_{H}$, and if the SIG fails to lobby then the state is $\theta_{L}$. For this equilibrium to exist, the SIG must prefer to refrain

14. Even when (1) fails, the truthful equilibrium is not unique. There always exists an equilibrium in which the DM distrusts the SIG's information and hence always sets the average policy. As a result, any signal by the SIG constitutes a best response. This equilibrium is not particularly interesting, however, and we will not consider it in the remainder of the paper.

15. In our model with only two possible states of the world, the set of sequential equilibria is equivalent to the set of perfect Bayesian equilibria. 
from lobbying when $\theta=\theta_{L}$, i.e., $-\left(\theta_{L}-\theta_{L}-\delta\right)^{2} \geq-\left(\theta_{H}-\theta_{L}-\delta\right)^{2}-l$, or $^{16}$

$l \geq \underline{l} \equiv\left(\theta_{H}-\theta_{L}\right)\left(2 \delta-\left(\theta_{H}-\theta_{L}\right)\right)$.

At the same time, the SIG must be willing to incur the lobbying cost when the state is high, i.e., $-\left(\theta_{H}-\theta_{H}-\delta\right)^{2}-l \geq-\left(\theta_{L}-\theta_{H}-\delta\right)^{2}$, which can be rewritten as

$l \leq \bar{l} \equiv\left(\theta_{H}-\theta_{L}\right)\left(2 \delta+\theta_{H}-\theta_{L}\right)$.

If both (2) and (3) hold, then the informative equilibrium described previously exists; in the remainder of the paper, we will focus on the case where an informative equilibrium exists, since it is only in this case that the corporate strategies we study are useful. Thus, a positive lobbying cost aids the SIG in truthful reporting by allowing it to express the intensity of its preferences. As we shall see in the subsequent sections, this result gives rise to a number of somewhat unexpected corporate strategies aimed at undermining the SIG's ability to communicate its views.

Letting $a \equiv\left(\theta_{H}-\theta_{L}\right)$, Figure 1 illustrates the values of $l$ and $a$ that give rise to a truthful reporting equilibrium. In this equilibrium, the SIG lobbies when the state is high and not when the state is low, and the DM holds the consistent beliefs that the state is high when the SIG lobbies and is low otherwise. The top line in the figure represents the combinations of $l$ and $a$ for which the SIG is just indifferent between lobbying when the true state of the world is $\theta_{H}$ and not lobbying in that state. Above this line, the SIG will choose not to incur the costs of lobbying even in the high state. The lower line traces out the combinations of $l$ and $a$ for which the SIG is just indifferent between lobbying in the low state (and falsely announcing $\theta_{H}$ ) and not lobbying in the low state. For all combinations of $l$ and $a$ below the lower line, the truthful reporting equilibrium fails to exist. To see this, suppose the DM believes he is playing the truthful equilibrium. For points below $\underline{l}$, the SIG then would have incentives to lobby in both states of the world, which is inconsistent with the posited beliefs of the DM. Thus, for $l<\underline{l}$, all equilibria are uninformative. ${ }^{17}$

Consider the case of siting a new paper-making facility, which will release some volume of organochlorines into a river. The facility

16. Note that with some rearranging of terms, the following expression reduces to (1) when $l=0$.

17. For some portions of the parameter space below $l$, it is possible to support an uninformative equilbrium in which the positive-biased SIG always lobbies if the DM holds the off-equilibrium belief that the state is $\theta_{L}$ should the SIG fail to lobby. Even when this equilibrium does not exist, however, there is always an uninformative equilibrium in which the DM believes the SIG's actions are uninformative (i.e., he does not update his prior regardless of the SIG's lobbying actions), so the SIG never lobbies. 


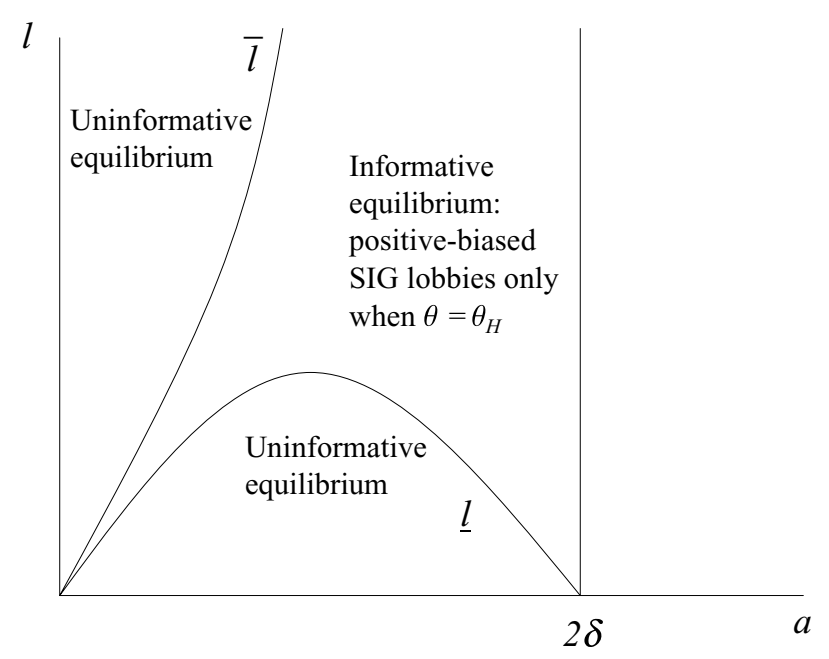

FIGURE 1. INTEREST GROUP LOBBYING BEHAVIOR

could use a number of alternative technologies for bleaching the pulp, which vary in their use of chlorine in the bleaching process and, thus, in the amount of organochlorines they release into the environment. A local environmental organization is concerned about organochlorine releases, since they result in the presence of trace amounts of dioxinsknown carcinogens-in the river downstream from the plant. Suppose condition (1) holds and lobbying is costless. In this case, the environmental group always will participate in hearings about the plant, and it will argue that dioxins are highly toxic chemicals whose release should be avoided, regardless of the bleaching technology to be used and the quantity of releases involved. Since the group always will protest regardless of the firm's technology, its actions convey little about the intensity of its concerns about the technology. If it is costly for the group to participate in the hearings, however, then the net benefits of participation are small when dioxins are released in minute amounts, so the group will eschew participation in that case. It will allocate its scarce lobbying resources to fighting the plant only when relatively large amounts of dioxins are likely to be released or when the downstream population is especially vulnerable. Thus, when lobbying is costly and when the local group does show up to participate in the proceedings, this is credible evidence that the harm from the plant's dioxin releases is likely to be large, i.e., the true state is $\theta_{H}{ }^{18}$

18. For further details on the issue of chlorine in the paper-making process, see Beckenstein et al. (1994). 
A very similar analysis applies when the SIG has a negative bias, i.e., $\delta<0$. Suppose that lobbying is costless $(l=0)$. Since the SIG always prefers a lower level of policy than does the DM, it has no incentive to misreport when the state is $\theta=\theta_{L}$. When $\theta=\theta_{H}$, however, the SIG will send a false report if

$\delta \leq-\left(\theta_{H}-\theta_{L}\right) / 2$.

If condition (4) holds, then the SIG always will report $\theta_{L}$, and the DM's optimal response to the SIG's announcement will be to set the average policy since the announcement is not credible. Paralleling our result for the positive-biased SIG, it is possible for the negative-biased SIG to lobby credibly-even when condition (4) holds-if lobbying is costly. In an informative equilibrium, the SIG only lobbies when the state is low, since a policy mistake in this state is very costly to the SIG; if the state is high, however, the SIG may find it too costly to lobby. For this equilibrium to exist, the SIG must prefer to refrain from lobbying when $\theta=\theta_{H}$, i.e., $-\left(\theta_{H}-\theta_{H}-\delta\right)^{2} \geq-\left(\theta_{L}-\theta_{H}-\delta\right)^{2}-l$, or

$l \geq \underline{l} \equiv\left(\theta_{H}-\theta_{L}\right)\left(-2 \delta-\left(\theta_{H}-\theta_{L}\right)\right)$.

Note that $\underline{l}>0$ since $\delta<0$.

At the same time, the SIG must be willing to incur the lobbying cost when the state is low, i.e., $-\left(\theta_{L}-\theta_{L}-\delta\right)^{2}-l \geq-\left(\theta_{H}-\theta_{L}-\delta\right)^{2}$, which can be rewritten as

$l \leq \bar{l} \equiv\left(\theta_{H}-\theta_{L}\right)\left(-2 \delta+\theta_{H}-\theta_{L}\right)$.

If both (5) and (6) hold, then an informative equilibrium exists.

An example of a lobbying game involving a negative-biased SIG would be a decision by lawmakers on whether to require the state to negotiate with pharmaceutical companies to obtain lower drug prices for Medicaid recipients. Suppose the consumer advocacy group Consumer Alliance strongly opposes such negotiations on the grounds that they would result in reduced choice in prescription drugs for senior citizens. If lobbying were costless, then Consumer Alliance would oppose any proposal regardless of the extent to which it limited choice. If, instead, Consumer Alliance had to expend resources to mount a grassroots campaign against draft legislation, then its decision to do so on any specific piece of legislation could serve as a useful signal of the extent to which the legislation would limit choice.

The remainder of the paper focuses on the role of the firm in the lobbying game. Before delving into this topic, however, we first discuss how the firm's payoff function differs from that of the SIG. Let the firm's 
objective function be $F=-\beta p^{2}$, where $\beta>0$. The parameter $\beta$ can be interpreted as an efficiency parameter: firms with large $\beta$ s tend to be less efficient at adapting to more stringent policies. The structure of the firm's objective function indicates that profits are strictly declining and convex in the stringency of the DM's policy, as is typical in economic models of regulation. This might be the case, for example, for the permitting requirements imposed on a proposed new manufacturing facility. The vast majority of the firm's shareholders do not live in the local community and hence are not affected directly by issues such as the availability of jobs within the community or environmental impacts of the plant. ${ }^{19}$ Assuming the DM is aware of the firm's objectives, then it is easy to see that the firm is not a credible source of information regarding the state of the world: since its payoff depends only on the policy set by the DM, and not on the state of the world, the firm will adopt exactly the same lobbying behavior in both states of the world regardless of the cost of lobbying. As a result, the DM cannot infer anything from the firm's lobbying activity, and, consequently, it is pointless for the firm to lobby the DM directly.

Although the firm cannot influence the DM directly, it has incentives to influence the lobbying activity of the SIG. In particular, we identify corporate strategies that can induce a switch from an informative equilibrium to an uninformative equilibrium. If the firm knows the state is high, then it can engage in astroturf lobbying to induce sympathetic interest groups to send a false report about the state to the decision-maker. If the firm does not know the state, then it can use the bear hug or self-regulation to induce other interest groups to undertake the same lobbying activity in all states. Regardless of the strategy employed, the decision-maker is deprived of information about the state, an outcome the firm finds profitable. In the case of astroturf, the firm profits by raising doubts about the true state when it is in fact high, inducing the DM to set the average policy rather than the high one. In the case of the bear hug or self-regulation, the concavity of the firm's profit function means the firm gains by keeping the DM uninformed, thereby ensuring itself the average policy outcome instead of a randomization between the low and high policies.

19. It would be possible to conduct the analysis under the assumption that the firm's payoff has the same structure as that of the SIG but that the firm's bias is so large that it cannot support an informative equilibrium, i.e., at least one of conditions (5) or (6) is violated. The analysis would be much more cumbersome, however, with no corresponding increase in generality or clarity. Indeed, if local environmental impacts play a small role in the firm's objectives, then a strictly declining objective function may represent the firm's preferences better than would a U-shaped function. Thus, we have chosen a parsimonious formulation that we believe captures the essence of the situation. 


\section{ASTROTURF}

In this section, we consider the corporate strategy of astroturf lobbying, in which the firm subsidizes the lobbying cost of a sympathetic special interest group after the firm learns the state of the world. Subsidy payments are made in states in which the special interest group normally would not lobby, ${ }^{20}$ and the resulting artificially induced lobbying is called astroturf lobbying. This strategy involves covertly supporting an interest group whose bias is negative; astroturf is thus a form of costly state falsification. ${ }^{21}$ As we noted in section 1, the most common examples of astroturfing involve the hiring of public relations or lobbying firms to stimulate artificial grassroots campaigns. The subsidies may be direct monetary payments, but they often involve providing free use of the firms' phone bank equipment and personnel. In the latter case, the employees of the public relations firm will pose as members of the grassroots group when they make phone calls or send faxes. ${ }^{22}$

The ex-post nature of the firm's subsidy payment (i.e., the fact it is made after the firm learns the state) is an important characteristic and distinguishes the strategy from the bear hug strategy, which involves an ex-ante contract with the SIG. In many situations, the firm will know the true state of the world prior to making its project proposal. For example, the literature on environmental justice argues that firms take community characteristics and impacts into account when deciding where to site industrial plants. ${ }^{23}$ In the context of health care reform, pharmaceutical companies presumably know in advance the true extent to which they will cut research and development (R\&D) spending if Medicaid reforms reduce the prices paid by the states for prescription drugs.

We will assume that conditions (4) through (6) hold, so an informative equilibrium exists. In this equilibrium, the negative-biased SIG lobbies in the low state but not in the high state. Can the firm use astroturf lobbying to raise its expected payoff relative to its payoff when the SIG engages in truthful lobbying behavior? Recall that for astroturf lobbying to work, the firm's subsidy to the negative-biased SIG must occur ex post and must be hidden from the DM. Although we assume that the DM cannot observe the firm's subsidy payment

20. Alternatively, the firm can subsidize an opposing SIG not to lobby when it normally would. The formal analysis is the mirror image of that discussed in the text. However, we are interested particularly in providing a positive political economy explanation for the observed behavior of astroturf lobbying, so we will limit our analysis to that case, which involves a negative-biased SIG.

21. Crocker and Tennyson (1999) study costly state falsification in the context of insurance and show that the optimal insurance contract typically involves a strictly positive amount of falsification.

22. For an example, see Craig (2002).

23. See Taylor (1992) or Greer and Harding (1993). 
costlessly, it is clear from our discussion in section 1 that policymakers are aware of the possibility of the astroturf lobbying strategy. Thus, we assume the DM can expend resources to create an auditing staff that may be able to determine whether a subsidy in fact did occur. Given the deluge of lobbying activity to which politicians are exposed, we will assume that resource constraints prevent the DM from hiring an auditing staff with the capacity to examine all lobbyists. Instead, we view the DM as committing a certain level of effort and resources to create an auditing staff that can audit a fraction $\alpha$ of the lobbying messages received. We will suppose that if a given lobbyist is selected for an audit, the DM obtains conclusive information about whether a subsidy was conferred. The (fixed) cost of hiring an auditing staff that can audit each SIG with probability $\alpha$ is $c(\alpha)$, where $c^{\prime}(\alpha)>0$ and $c^{\prime \prime}(\alpha)>0$. We also will assume that $\lim _{\alpha \rightarrow 0} c^{\prime}(\alpha)=0$ and $\lim _{\alpha \rightarrow 1} c^{\prime}(\alpha)=\infty$, which assures an interior solution. In the analysis to follow, then, we interpret the DM's auditing process as reflecting a precommitment to audit each SIG with probability $\alpha$.

There are two possible types of equilibria with auditing: one in which astroturf does not occur, and one in which it does.

\subsection{THE "NO-ASTROTURF" EQUILIBRIUM}

In this equilibrium, the DM believes (correctly) that if the SIG lobbies then the state is $\theta_{L}$, and if the SIG does not lobby then the state is $\theta_{H}$. To ensure that these conditions hold, however, the DM must audit the SIG when it lobbies in order to eliminate the firm's incentives to astroturf. Assuming the firm does not engage in astroturf lobbying, the DM can infer correctly the state of the world and sets the optimal policy for each state. Let the DM's equilibrium audit probability in this case be $\alpha^{N A}$. Thus, the DM's expected payoff is $G^{N A}=-c\left(\alpha^{N A}\right)$, since aside from the cost of auditing, setting the correct policy generates a loss of zero in both states.

In order for the no-astroturf equilibrium to exist, it must be unprofitable for the firm and the SIG to engage in astroturf. Astroturf lobbying would consist of the firm covertly paying the SIG to lobby in the high state. The smallest amount the SIG would accept is $S^{N A}(\delta, l)$, where the superscript $N A$ indicates that we are examining the no-astroturf equilibrium. The amount the firm must pay the SIG is determined by what it will take in the high state to make the SIG indifferent between lobbying and getting the low policy if it is not audited [which occurs with probability $\left(1-\alpha^{N A}\right)$ ] and not lobbying and getting the high policy for certain. Formally, $S^{N A}(\delta, l)$ is determined by

$$
\begin{gathered}
-\left(1-\alpha^{N A}\right)\left(\theta_{L}-\theta_{H}-\delta\right)^{2}+S^{N A}(\delta, l)-l \\
=-\left(1-\alpha^{N A}\right)\left(\theta_{H}-\theta_{H}-\delta\right)^{2},
\end{gathered}
$$


which yields

$S^{N A}=l+\left(1-\alpha^{N A}\right)\left(\theta_{H}-\theta_{L}\right)\left(2 \delta+\theta_{H}-\theta_{L}\right)$.

Note that since the DM believes she is playing the no-astroturf equilibrium, lobbying leads the DM to believe the state is really $\theta_{L}$ (assuming an audit does not prove otherwise) and hence to set the low policy. Clearly $S^{N A}(\delta, l)$ is less than $l$, since the SIG derives direct utility from obtaining $\theta_{L}$. (Henceforth, we suppress the dependence of $S^{N A}$ on $\delta$ and $l$ for notational simplicity.) Because we are considering the case where $\delta<0, S^{N A}$ is smaller the more biased is the SIG.

Conditional on the DM's commitment to an audit policy and on the DM's recognition that he is playing the no-astroturf equilibrium, the firm must prefer not to astroturf in state $\theta_{H}$. (It need not engage in astroturf in state $\theta_{L}$, as the SIG lobbies by assumption.) The firm's profits if it does not astroturf are $\pi^{N A}\left(\theta_{H}\right)=-\beta \theta_{H}^{2}$. If it were to astroturf, by paying the SIG an amount $S^{N A}$, its expected profits would be

$\bar{\pi}^{A}\left(\theta_{H}\right)=\alpha^{N A}\left(-\beta \theta_{H}^{2}\right)+\left(1-\alpha^{N A}\right)\left(-\beta \theta_{L}^{2}\right)-S^{N A}$.

Thus, with probability $\alpha^{N A}$, the DM conducts an audit, and the audit reveals that the firm engaged in astroturf; the DM then sets a high level of policy. With probability $1-\alpha^{N A}$ the DM does not audit; since the DM believes the no-astroturf equilibrium is being played and has no evidence to the contrary, she sets a low level of policy.

A "No-Astroturf" equilibrium requires $-\beta \theta_{H}^{2}>\alpha^{N A}\left(-\beta \theta_{H}^{2}\right)+(1-$ $\left.\alpha^{N A}\right)\left(-\beta \theta_{L}^{2}\right)-S^{N A}$. This can be rewritten as

$\left(1-\alpha^{N A}\right) \beta\left(\theta_{H}^{2}-\theta_{L}^{2}\right)-S^{N A}<0$.

In order to enforce the no-astroturf equilibrium, the DM must choose $\alpha^{N A}$ to make inequality (8) hold. This implies

$\alpha^{N A} \geq 1-\frac{S^{N A}}{\beta\left(\theta_{H}^{2}-\theta_{L}^{2}\right)}$.

Note that as $S^{N A}$ becomes smaller and as $\beta$ or the gap between $\theta_{H}$ and $\theta_{L}$ becomes larger, the DM must audit with a higher probability in order to maintain the "No-Astroturf" equilibrium. In fact, as $S^{N A}$ goes to zero, the cost of auditing becomes prohibitive, and the no-astroturf equilibrium fails to exist.

\subsection{THE "ASTROTURF" EQUILIBRIUM}

Next we consider the existence of an alternative equilibrium in which it is common knowledge that the DM does not audit enough to deter astroturf lobbying. In this equilibrium, the SIG always lobbies regardless 
of the state of the world: in the low state the SIG itself is motivated to lobby, while in the high state the firm pays the SIG to lobby. As a result, the DM always sets the average policy unless an audit catches the firm engaging in astroturf, in which case the DM knows the state is $\theta_{H}$ and sets a stringent policy. We will assume that if the SIG does not lobbywhich is an out-of-equilibrium event-then the DM believes the state must be $\theta_{H}$ and sets $p=\theta_{H}$. This off-equilibrium belief seems reasonable given that the SIG's incentive to lobby is weaker in the high state than in the low state.

Let us consider the SIG's optimal lobbying strategy in each state of the world. Suppose the state is $\theta=\theta_{L}$. The SIG obtains policy $p=$ $\left(\theta_{H}+\theta_{L}\right) / 2$ if it lobbies and policy $p=\theta_{H}$ if it does not. Lobbying is worthwhile if $-\left(\left(\theta_{H}+\theta_{L}\right) / 2-\theta_{L}-\delta\right)^{2}-l \geq-\left(\theta_{H}-\theta_{L}-\delta\right)^{2}$, which can be rewritten as

$l \leq \bar{l}^{\prime} \equiv\left(\theta_{H}-\theta_{L}\right)\left(3\left(\theta_{H}-\theta_{L}\right) / 4-\delta\right)$.

Now suppose the state is $\theta=\theta_{H}$. Again, the SIG obtains policy $p=\left(\theta_{H}+\theta_{L}\right) / 2$ if it lobbies and policy $p=\theta_{H}$ if it does not. Lobbying is not worthwhile if

$-\left(\theta_{H}-\theta_{H}-\delta\right)^{2}>-\left(\left(\theta_{H}+\theta_{L}\right) / 2-\theta_{H}-\delta\right)^{2}-l$.

This can be rewritten as

$l \geq \underline{l}^{\prime} \equiv \frac{\left(\theta_{H}-\theta_{L}\right)}{2}\left[-2 \delta-\frac{\left(\theta_{H}-\theta_{L}\right)}{2}\right]$.

If both (10) and (11) hold, then in equilibrium the SIG's optimal strategy is to lobby only in the low state (unless it is subsidized by the firm to lobby in the high state). ${ }^{24}$ Figure 2 illustrates the curves $\bar{l}^{\prime}$ and $l^{\prime}$ in relation to the curves $\bar{l}$ and $\underline{l}$ derived in section 2 . The mathematical formulation of the curves differs now because in the simple model, if the SIG lobbies it expects the DM to set the policy it advocates, whereas in the astroturf equilibrium, lobbying yields only the average policy. As a result, lobbying is less productive for the SIG, and the curves for the astroturf equilibrium effectively are "stretched" to the right, though they maintain the same general shape as the original curves.

Assuming $l \in\left[l^{\prime}, \bar{l}^{\prime}\right]$, how much must the firm subsidize the SIG in order to induce it to accept astroturf funding? Let $S^{A}(\delta, l)$ be the minimum the SIG will accept, which is defined by the equality

$$
\begin{aligned}
& -\alpha^{A}\left(\theta_{H}-\theta_{H}-\delta\right)^{2}-\left(1-\alpha^{A}\right)\left(\left(\theta_{H}+\theta_{L}\right) / 2-\theta_{H}-\delta\right)^{2}-l+S^{A}(\delta, l) \\
& =-\left(\theta_{H}-\theta_{H}-\delta\right)^{2} .
\end{aligned}
$$

24. Note that $\underline{l}^{\prime}>0$ and $\bar{l}^{\prime}>0$ since $\delta<-\left(\theta_{H}-\theta_{L}\right) / 2$. 


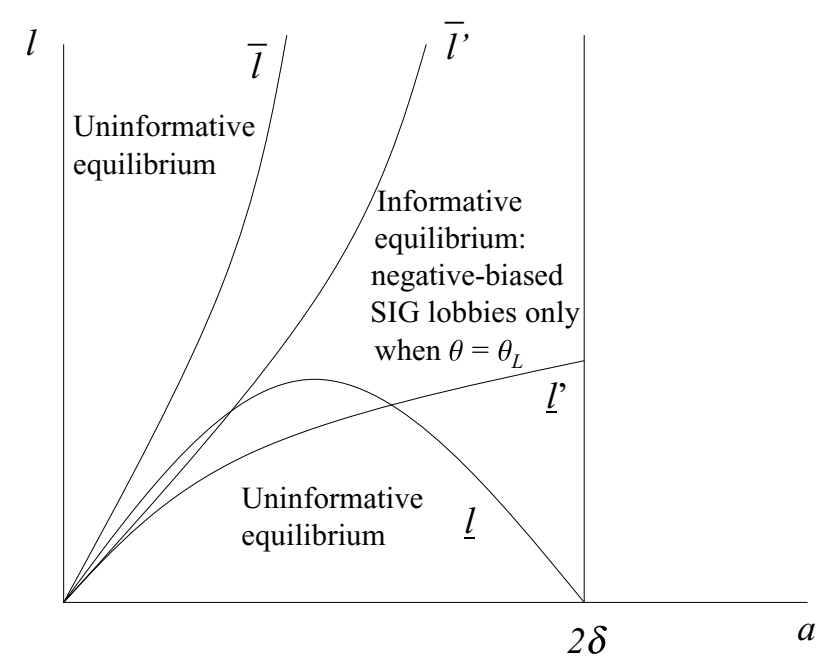

FIGURE 2. EXISTENCE OF ASTROTURF EQUILIBRIUM

For any subsidy greater than $S^{A}(\delta, l)$, the SIG is willing to accept the payment and lobby, obtaining the average policy, rather than choosing to not lobby, thereby obtaining the high policy. Clearly, $S^{A}(\delta, l)<l$, since the firm prefers the average policy to the high policy. (Henceforth, we suppress the dependence of $S^{A}$ on $\delta$ and $l$ for notational simplicity.)

For the region where $l \in\left(l^{\prime}, \bar{l}^{\prime}\right)$, the astroturf equilibrium exists if the firm finds it profitable to subsidize the SIG's lobbying activity when the state is high. If $\theta=\theta_{H}$ and if the firm chooses to engage in astroturf by subsidizing the SIG with a payment of $S^{A}$, then

$\bar{\pi}^{A}\left(\theta_{H}\right)=\alpha^{A}\left(-\beta \theta_{H}^{2}\right)+\left(1-\alpha^{A}\right)\left[-\beta\left(\frac{\theta_{H}+\theta_{L}}{2}\right)^{2}\right]-S^{A}$.

The firm's expected profits reflect the fact that the stringent policy is imposed only if an audit reveals that astroturf lobbying occurred; this happens with probability $\alpha^{A}$. Otherwise, the DM sets the average policy since she believes (correctly) that the astroturf equilibrium is being played.

If the firm did not pay for astroturf lobbying when the state was $\theta=\theta_{H}$, then the SIG would not lobby. As noted already, this is out-ofequilibrium behavior, given that the DM believes they are playing the astroturf equilibrium, and we assume that in this event the DM believes the state is $\theta_{H}$ and sets $p=\theta_{H}$. As a result, the firm earns $\pi=-\beta \theta_{H}^{2}$. To 
ensure this deviation from equilibrium play does not occur, it must be the case that $\bar{\pi}^{A}\left(\theta_{H}\right)>-\beta \theta_{H}^{2}$. That is, an astroturf equilibrium requires

$\alpha^{A}\left(-\beta \theta_{H}^{2}\right)+\left(1-\alpha^{A}\right)\left[-\beta\left(\frac{\theta_{H}+\theta_{L}}{2}\right)^{2}\right]-S^{A}+\beta \theta_{H}^{2}>0$,

which implies

$\frac{1-\alpha^{A}}{4} \beta\left(3 \theta_{H}+\theta_{L}\right)\left(\theta_{H}-\theta_{L}\right)>S^{A}$.

Since $S^{A}<l \leq \bar{l}^{\prime}$, a sufficient condition for (13) is

$\frac{1-\alpha^{A}}{4} \beta\left(3 \theta_{H}+\theta_{L}\right)\left(\theta_{H}-\theta_{L}\right) \geq\left(\theta_{H}-\theta_{L}\right)\left(3\left(\theta_{H}-\theta_{L}\right) / 4-\delta\right) \equiv \bar{l}^{\prime}$,

which can be rewritten as

$\beta \geq \frac{3\left(\theta_{H}-\theta_{L}\right)-4 \delta}{\left(1-\alpha^{A}\right)\left(3 \theta_{H}+\theta_{L}\right)}$.

Thus, we obtain the following lemma.

Lемма 1: For $\beta$ satisfying inequality (15), the firm finds it profitable to fund the SIG to engage in astroturf lobbying.

Lemma 1 states that if the firm's payoff function is sufficiently concave, then it is profitable to engage in the astroturf strategy, i.e., to subsidize the SIG in the high state of the world even when it faces a positive probability of detection. In doing so, the firm benefits from obtaining the average policy in the high state (as long as an audit does not detect the subsidy), although it does sacrifice the possibility of obtaining $p=\theta_{L}$ (obtaining the average policy instead) when the state of the world is low. ${ }^{25}$

Finally, to determine whether an astroturf equilibrium exists, we need to check whether the DM would prefer to deter astroturf and shift to

25. Since the firm's benefit from astroturf is simply that it obtains the average policy (except when an audit catches the firm engaging in astroturf lobbying), the reader may wonder why the firm instead does not contract with the SIG never to lobby. The latter strategy - if feasible - would appear to generate greater joint surplus, since it avoids the cost of lobbying and also avoids the risk that the DM sets the high policy when the firm is caught engaging in astroturf. However, such a contract is not feasible under the conditions in which astroturf lobbying is used, i.e., when the firm knows the state is high. A contract paying the SIG never to lobby must be written before the firm learns the state of the world, since if the state is low then the firm likes the informative equilibrium, and would not pay the SIG to stay home and to eschew lobbying. 
the no-astroturf equilibrium. The DM's expected utility in the astroturf equilibrium is

$$
\begin{aligned}
G^{A}= & \frac{1}{2}\left[\alpha^{A}(0)+\left(1-\alpha^{A}\right)\left(-\left(\frac{\theta_{H}+\theta_{L}}{2}-\theta_{L}\right)^{2}\right)\right] \\
& +\frac{1}{2}\left[\alpha^{A}(0)+\left(1-\alpha^{A}\right)\left(-\left(\frac{\theta_{H}+\theta_{L}}{2}-\theta_{H}\right)^{2}\right)\right]-c\left(\alpha^{A}\right) \\
= & -\left(1-\alpha^{A}\right) \frac{\left(\theta_{H}-\theta_{L}\right)^{2}}{4}-c\left(\alpha^{A}\right) .
\end{aligned}
$$

Given our assumptions about $c(\alpha)$, an interior solution is assured. ${ }^{26}$ Alternatively, in the no-astroturf equilibrium, the DM always sets the optimal policy and hence incurs no policy loss but must expend auditing resources when lobbying occurs, obtaining a net utility $G^{N A}=-c\left(\alpha^{N A}\right)$. The DM prefers the astroturf equilibrium if $G^{A}>G^{N A}$, that is, if

$-\left(1-\alpha^{A}\right) \frac{\left(\theta_{H}-\theta_{L}\right)^{2}}{4}-c\left(\alpha^{A}\right)>-c\left(\alpha^{N A}\right)$.

It is evident that the astroturf equilibrium is preferred by the DM if $\alpha^{N A}$ is very high and/or the audit cost function is highly convex. Thus, we have the following proposition:

Proposition 1: An astroturf equilibrium exists when conditions (4), (10), (11), (15), and (17) hold.

In summary, we have demonstrated that a firm may be able to engage profitably in the practice of astroturfing and that the DM may be unable to prevent this. ${ }^{27}$ Taken as a whole the results of this section lead to the following proposition.

PRoposition 2: The public decision-maker would be better off if the firm were required to disclose publicly its expenditures on astroturf lobbying.

Proof. Suppose the conditions in Proposition 1 hold. If public disclosure of expenditures on astroturf lobbying were required, then the DM always would be able to infer the state correctly, to set the optimal policy for each state, and to obtain expected payoff $G^{0}=0$. If the possibility of astroturf lobbying exists, one of two equilibria will result.

26. The DM's auditing decision in the astroturf equilibrium is determined by the firstorder condition $\partial G^{A} / \partial \alpha=\left(\theta_{H}-\theta_{L}\right)^{2} / 4-c^{\prime}\left(\alpha^{A}\right)=0$.

27. As mentioned earlier, if the firm faces a positive-biased SIG, then it could be profitable to the SIG not to lobby in the high state, although this practice properly cannot be termed astroturf lobbying. It is not incentive compatible for the firm to pay a negativebiased SIG not to lobby, since in the low state the firm prefers to have the SIG lobby for a lax policy. 
In the no-astroturf equilibrium the DM's expected payoff is $G^{N A}=$ $-c\left(\alpha^{N A}\right) / 2<G^{0}$, and in the astroturf equilibrium the DM's expected payoff is $G^{A}=-\left(1-\alpha^{A}\right)\left(\theta_{H}-\theta_{L}\right)^{2} / 4-c\left(\alpha^{A}\right)<G^{0}$.

Proposition 2 illustrates why decision-makers may want to pass laws requiring the reporting of funding devoted to astroturf lobbying. Interestingly, this desire will exist even when efforts aimed at detecting astroturf are successful enough to deter the activity, since the DM must expend real resources on auditing to deter astroturf lobbying and hence receives a strictly negative payoff even in the no-astroturf equilibrium.

A key feature of astroturf lobbying is its covert nature. On December 19, 1995, President Bill Clinton signed into law the Lobbying Disclosure Act of 1995, establishing new registration and reporting requirements for lobbyists working for corporations, charities, and other nonprofit organizations engaged in efforts to influence legislative and executive branch decisions. The 1995 act was the first major legislation on lobbying in nearly 50 years and was designed to provide transparency in the lobbying process. Early drafts of the Lobbying Disclosure Act included provisions requiring the registration of firms engaged in astroturf lobbying and the reporting of the expenditures made on those actions. Those provisions, however, failed to make it out of committee. As the bill's sponsor, Senator Carl Levin, testified before a House committee considering the bill: "Every reference to grass roots lobbying - and even to paid efforts to stimulate artificial grass roots lobbying - has been deleted from the bill ... I am personally disappointed that we were unable to do anything to address the issue of a form of grassroots lobbying referred to as astroturf lobbying, in which lobbyists hire professional experts to run phone banks and generate mail in support of their efforts. In my view, these paid, professional astroturf campaigns bear nothing in common with the genuine grassroots activities... I... hope that the House will reconsider the disclosure of such lobbying..."28

Thus, a significant and growing aspect of the lobbying process remains obscured from public view. Even if disclosure were required, however, it would not be a panacea. In the following two sections we explore two alternative corporate strategies that also impede the ability of special interest groups to provide information to the decision-maker. These strategies involve overt rather than covert actions on the part of the firm and therefore would be unaffected by any public reporting requirements.

28. Testimony of Senator Carl Levin, Committee on the Judiciary, Subcommittee on the Constitution, U.S. House of Representatives, September 7, 1995. 


\section{THE BEAR HUG}

In this section we explore the use of publicly observable payments by the firm that are aimed at influencing the lobbying behavior of special interest groups. We show that the firm may wish to make these payments to SIGs with either a negative or a positive bias and that the firm can pay either the SIG never to lobby, regardless of the state, or always to lobby. For simplicity, we focus on the case of a SIG with a positive bias. This case sheds light on the seemingly odd situation in which an interest group such as Greenpeace accepts funding for its communication efforts from a large oil company such as Shell. We begin our analysis under the assumption that the firm and the SIG can commit credibly not to renegotiate a contract governing the SIG's lobbying behavior. In section 4.2 , we turn to the case where renegotiation is possible and study the restrictions this places on the use of the bear hug strategy.

\subsection{CONTRACTING WITH COMMITMENT}

We assume there exists a positive-biased SIG for which conditions (1) through (3) hold..$^{29}$ Then, as we have shown, there exists an equilibrium in which the SIG's lobbying activity fully reveals to the DM the true state of the world. In this subsection we explore the firm's relationship with the SIG under these circumstances. We assume the firm can commit credibly to a contract with the SIG to adopt a particular lobbying strategy and examine when such a contract is incentive compatible for both parties. Note that since the state of the world is not verifiable in court, the contract cannot condition upon the state.

Given the convexity of the firm's payoff function, the bear hug contract is effectively a form of insurance against adverse policy outcomes, since the firm receives the average policy $p=\left(\theta_{H}+\theta_{L}\right) / 2$ with certainty rather than a randomization between $p=\theta_{L}$ and $p=\theta_{H}$. The following lemma provides an upper bound on the amount the firm is willing to pay for this insurance.

Lemma 2: If conditions (1) through (3) or (4) through (6) hold, then the firm is willing to pay up to $\beta\left(\theta_{H}-\theta_{L}\right)^{2} / 4$ to induce a switch from an informative to an uninformative equilibrium.

Proof. In an informative equilibrium, the firm's expected payoff is $E(F)=-\beta \theta_{L}^{2} / 2-\beta \theta_{H}^{2} / 2=-\beta\left(\theta_{L}^{2}+\theta_{H}^{2}\right) / 2$. Alternatively, in an uninformative equilibrium, it is optimal for the DM to set a policy simply based on its prior, in which case the firm's payoff is $F=-\beta\left(\theta_{H}+\theta_{L}\right)^{2} / 4$. The difference between these two payoffs is $\beta\left(\theta_{H}-\theta_{L}\right)^{2} / 4>0$.

29. All of our results in this section also go through if the SIG is negative-biased. 
The intuition behind the Lemma 2 is straightforward. The firm's payoff is concave with respect to the stringency of policy, so Jensen's Inequality implies that the firm prefers the average policy to a lottery between the low and high policies. By paying the SIG to take the same action in both states of the world, the firm destroys the informative equilibrium and reduces the DM to adopting the policy $p=\left(\theta_{L}+\theta_{H}\right) / 2$, its optimal choice when the state of the world is unknown. The bear hug strategy is thus a form of signal jamming, similar in spirit to the analysis of Fudenberg and Tirole (1986) in the context of predation. ${ }^{30}$ Leema 2 identifies the firm's gross benefit from using the bear hug strategy to shift from an informative to an uninformative equilibrium. This can be accomplished most cheaply by paying the SIG never to lobby. Equivalent results can be obtained, however, if the firm subsidizes the SIG always to lobby, e.g., by undertaking actions such as funding the reporting of information by environmental or local community organizations, covering the SIG's travel costs for appearing before the decision-maker, and soforth. Such private-sector funding appears to be increasingly common. For example, one major national environmental group has adopted a policy of accepting funding from corporations to participate in regulatory negotiations. ${ }^{31}$ While the second approach is more costly, it might be more palatable politically for a SIG that does not want to appear to be bribed into silence by corporations normally perceived as its adversaries. In a related vein, the SIG may receive some (unmodeled) benefits from lobbying that might lead it to prefer being subsidized to lobby rather than being paid to stay home. For example, SIGs may find that the greater media coverage that comes with lobbying has a positive effect on their fund-raising efforts.

Even when the firm wishes to offer the bear hug, the SIG must be willing to accept the firm's support. Consider first the case where the firm pays the SIG never to lobby. This will be acceptable to the SIG if it prefers to obtain the average policy outcome plus a subsidy $S^{B}$ rather than incur the lobbying cost $l$ in the high state to deliver credibly the report $\theta_{H}$. Mathematically, the SIG must prefer .5[ $-\left(\left(\theta_{H}+\theta_{L}\right) / 2-\theta_{H}-\right.$ $\left.\delta)^{2}\right]+.5\left[-\left(\left(\theta_{H}+\theta_{L}\right) / 2-\theta_{L}-\delta\right)^{2}\right]+S^{B}$ to $-\delta^{2}-l / 2$. Rearranging terms, we find the SIG is willing to accept subsidy $S^{B}$ if

$S^{B}>\left(\theta_{H}-\theta_{L}\right)^{2} / 4-l / 2$.

30. Note that the lobbying activities of a negatively biased SIG also can inform the DM of the true state; in this case, the SIG only lobbies when the state is low. Since the firm prefers that the DM not know the state of the world, signal jamming through the use of the bear hug can be valuable for a negatively biased SIG as well as one with a positive bias.

31. Private communication with Dallas Burtraw, Senior Fellow at Resources for the Future, December 20, 2002. 
It also is conceivable that for political reasons the SIG would prefer not to be seen accepting a "bribe" that requires it to eschew lobbying on a particular issue. An alternative is for the firm to subsidize the SIG always to lobby. This is more expensive for the SIG by the amount $l$, so the subsidy it demands then will be

$S^{B}>\left(\theta_{H}-\theta_{L}\right)^{2} / 4+l / 2$.

Comparing the foregoing conditions to the firm's profitability condition $S^{B} \leq \beta\left(\theta_{H}-\theta_{L}\right)^{2} / 4$, we are led immediately to the following proposition.

Proposition 3: Assume conditions (1) through (3) or (4) through (6) hold. The bear hug is incentive compatible (i.e., profitable to the firm and accepted by the SIG) if (a) $\beta>1-2 l /\left(\theta_{H}-\theta_{L}\right)^{2}$ and the firm pays the SIG never to lobby; or (b) $\beta>1+2 l /\left(\theta_{H}-\theta_{L}\right)^{2}$ and the firm pays the SIG always to lobby.

Clearly $\beta \geq 1$ is a sufficient condition for the bear hug to be incentive compatible when the firm pays the SIG never to lobby. Both parties would prefer this to the bear hug in which the SIG always lobbies. Nevertheless, the bear hug in which the SIG always lobbies is also incentive compatible for large enough $\beta$ and may be used if political considerations (unmodeled here) make it unacceptable for the SIG to accept a payment to eschew lobbying. ${ }^{32}$

The effects of the bear hug on the DM's expected utility are shown; Proposition 4.

Proposition 4: The bear hug strategy reduces the public decisionmaker's expected payoff relative to the full information case.

Proof. Without the subsidy, the DM's expected utility is $E(G)=0$. The SIG can be relied upon to reveal the true state, and the DM thus can tailor policy perfectly to each state of the world. When the firm subsidizes the SIG, the DM's expected utility is $E\left(G^{B H}\right)=(1 / 2)\left[-\left(\left(\theta_{L}+\theta_{H}\right) / 2-\theta_{L}\right)\right]^{2}+$ $(1 / 2)\left[-\left(\left(\theta_{L}+\theta_{H}\right) / 2-\theta_{H}\right)\right]^{2}=-\left(\theta_{H}-\theta_{L}\right)^{2} / 4<0$. Hence the DM is worse off when the firm supports the SIG.

The proposition shows that under conditions (1) through (3) or (4) through (6), the DM is strictly worse off when the firm provides financial support to the SIG. While signal jamming is profitable for the firm and may be accepted by the SIG as a way to economize on lobbying costs,

32. In the text we have considered only the existence of pure-strategy equilibria. Mixedstrategy equilibria in which the firm randomizes its subsidy offers also are possible and may be more profitable for the firm. A proof is available from the authors upon request. Note that in a mixed strategy equilibrium, the DM does not observe directly whether the subsidy took place; rather, it simply believes (perhaps based on the firm's past behavior) that the firm is engaging in mixing behavior. 
it is unwelcome to the decision-maker because it prevents the optimal matching of policy to circumstances.

There are three potential issues that may limit the conditions under which the bear hug is a viable strategy. First, the strategy must apply to situations where the true state of the world is unknown to the firm at the time the subsidy is granted. The reason for this restriction is as follows. If the firm knew the true state of the world was $\theta_{L}$, it would prefer that the conditions of truthful revelation held. These conditions would require that no subsidy be given, so the SIG eschews lobbying. If the firm knew the state was $\theta_{H}$, however, it would have incentives to pay the SIG publicly not to lobby, so as to undermine the DM's ability to infer the state. Thus, if the firm knew the true state, its subsidy would be state dependent, and the DM could determine the true state simply by observing whether the subsidy payment had been made. In consequence, the bear hug strategy is more likely to apply to situations with true scientific uncertainty or situations with a risk of accidents than to situations where the firm knows the state in advance. The bear hug thus can be seen as a kind of insurance policy against worst-case policy outcomes.

The second issue affecting the viability of the bear hug is that the firm must be able to contract directly on the SIG's lobbying actions on a particular issue. If this is infeasible for political or other reasons, then the firm must ensure that its subsidy is used to subsidize the SIG's lobbying costs on the particular issue of concern. Thus, there may be difficulties implementing the bear hug strategy if the SIG operates in multiple policy arenas. A general-purpose gift to an environmental group may go simply to subsidize the group's fixed costs but may not guarantee that extra funds are devoted to lobbying about dioxin. The firm must be able to tie the gift to SIG activity in a particular issue area. This might be done by providing the SIG with a forum in which it can express its views. For example, in the paper industry example, the environmental group could be invited to participate in a paper industry forum, at the industry's expense, thereby targeting the support toward a particular issue.

The third issue that constrains the viability of the bear hug is that the parties may have incentives to renegotiate the contract after they learn the state of the world, which may undermine the effectiveness of the strategy. We discuss this issue in detail in the following subsection.

\subsection{RenEgotiation of the Bear Hug}

To this point, we have assumed that the firm can commit credibly to a contract with the SIG in which the SIG is rewarded on the basis of its 
lobbying behavior, although the contract cannot be conditioned on the (unverifiable) state of the world. Now we turn to the question of whether such a contract would remain viable if renegotiation were possible. A maintained assumption throughout our analysis of the bear hug is that the firm's contract with the SIG is observable by the DM, so we assume that any renegotiation of that contract also is observable. As a result, if incentives for renegotiation differ across states of the world, the DM can infer the state from the parties' renegotiation actions. As might be expected, incentives for renegotiation depend upon $\beta, \delta$, and $l$. These parameters determine the costs and benefits of renegotiation for the firm and the SIG. We find that the possibility of renegotiation restricts the set of parameters for which the bear hug is a viable contract.

To illustrate the sort of analysis involved, we begin with the case of a contract paying a negative-biased SIG always to lobby and show that such a contract is always vulnerable to renegotiation and hence cannot restrain the SIG's lobbying activity credibly. We then present briefer discussions of a contract with a negative-biased SIG never to lobby and contracts with a positive-biased SIG.

Recall that in an informative equilibrium with a negative-biased SIG, the SIG lobbies if the state is low and not otherwise. The bear hug contract we consider here involves the firm paying the SIG to lobby in both states and the DM imposing the average policy. The DM believes that in the off-equilibrium event that the SIG does not lobby, then the state is high. ${ }^{33}$ Do the parties want to rip up the contract ex post and renegotiate?

When $\theta=\theta_{L}$, both parties gain if the state is revealed to the DM, and he sets a corresponding level of policy. This can be accomplished if the firm pays the SIG the agreed-upon subsidy level, and then the parties tear up the contract. With the contract out of the way, the informative equilibrium becomes feasible once again, and we assume the game reverts to it. Since the state is low, the SIG chooses to lobby, and the DM sets the low policy. The net gain to the SIG is

$-\left(\theta_{L}-\theta_{L}-\delta\right)^{2}+\left(\left(\theta_{H}+\theta_{L}\right) / 2-\theta_{L}-\delta\right)^{2}=\left(\theta_{H}-\theta_{L}\right)^{2} / 4-\delta\left(\theta_{H}-\theta_{L}\right)$,

while the gain to the firm is

$-\beta \theta_{L}^{2}+\beta\left(\theta_{H}+\theta_{L}\right)^{2} / 4=\beta\left(\theta_{H}+3 \theta_{L}\right)\left(\theta_{H}-\theta_{L}\right) / 4$.

33. If the off-equilibrium belief were that the state is low, then the bear hug contract we are considering would not be an equilibrium, even if the parties had full commitment power. 
Renegotiation will occur as long as the increase in joint surplus is positive, i.e., if

$$
\begin{array}{r}
\beta\left(\theta_{H}+3 \theta_{L}\right)\left(\theta_{H}-\theta_{L}\right) / 4+\left(\theta_{H}-\theta_{L}\right)^{2} / 4-\delta\left(\theta_{H}-\theta_{L}\right) \\
=\left(\theta_{H}-\theta_{L}\right)\left[\beta\left(\theta_{H}+3 \theta_{L}\right)+\left(\theta_{H}-\theta_{L}\right)-4 \delta\right] / 4>0 .
\end{array}
$$

Since $\delta<0$, this expression is always true, and hence renegotiation always will occur in the low state. ${ }^{34}$ If renegotiation does not occur in the high state, then the DM can infer the state by observing the renegotiation behavior of the parties. Conversely, if renegotiation occurs in both states, then there is no point to writing the original contract. Either way, a bear hug contract paying a negative-biased SIG always to lobby is undermined by renegotiation.

Matters are more complicated somewhat if the firm contracts with the negative-biased SIG never to lobby. Now, in state $\theta_{L}$, the parties prefer a low policy to the average one, but lobbying resources must be expended in order to achieve it. As a result, renegotiation will occur in the low state unless $l$ is sufficiently large, i.e., unless

$l>\left(\theta_{H}-\theta_{L}\right)\left[\beta\left(\theta_{H}+3 \theta_{L}\right)+\left(\theta_{H}-\theta_{L}\right)-4 \delta\right] / 4$.

Thus, for lobbying costs below this threshhold, a bear hug contract that pays the negative-biased SIG always to stay home is not renegotiation-proof. The firm desiring to influence the SIG's behavior must utilize astroturf lobbying (or self-regulation) instead of the bear hug.

Similar analyses can be conducted for bear hug contracts with a positive-biased SIG. The joint surplus from renegotiation is lower than for the negative-biased SIG, though, since the parties prefer different policy outcomes. For example, consider a bear hug contract with the positive-biased SIG always to lobby. In state $\theta_{L}$, the firm desires to renegotiate the contract, so as to obtain the low policy instead of the average policy. In contrast, the SIG prefers the average policy, other things equal, although renegotiation does offer the benefit that the SIG does not incur the lobbying cost $l$. The increase in joint surplus from renegotiation can be shown to be

$$
\left(\theta_{H}-\theta_{L}\right)\left[\frac{(\beta+1) \theta_{H}+(3 \beta-1) \theta_{L}}{4}-\delta\right]+l
$$

Clearly renegotiation will only be jointly beneficial if $\beta$ or $l$ is large enough or if $\delta$ is small enough. Note the contrast with the result for the

34. Note that in this type of bear hug contract, incentives for renegotiation do not depend on $l$. Since the SIG will lobby whether or not the contract is in force, $l$ is incurred regardless of renegotiation. 
negative-biased SIG, in which case the parties always renegotiate this type of contract, regardless of parameter values. This type of reasoning holds also for a bear hug paying the SIG never to lobby: in both cases, the fact that the firm and the SIG have differing preferences over policies limits the value of renegotiation. In summary, bear hug contracts with a positive-biased SIG are less vulnerable to renegotiation, implying that they are more likely to be observed in practice.

\section{Self-REgulation}

Each of the strategies we have considered thus far has limitations. Astroturf is possible only when the firm already knows the state of the world and when firms are not required to disclose their expenditures publicly on this form of lobbying. The bear hug requires commitment power and may be undermined by renegotiation. In this section, we study the possibility that the firm may be able to alter the SIG's lobbying behavior by reducing the severity of the high state, i.e., reducing $\theta_{H}$, through voluntary improvements made $e x$ ante. This might be done, for example, through design measures for a new facility that reduce the impact of worst-case outcomes. If the DM has the power to hold the firm to the design it proposes, such actions constitute credible commitments.

The basic intuition here is that if the difference between the high and low states is sufficiently small, then the SIG will have little motivation to lobby the DM. Hence, self-regulation by the firm may induce the SIG to eschew lobbying, with the result that the DM sets the average policy, and the firm's profits rise by $\beta\left(\theta_{H}-\theta_{L}\right)^{2} / 4$, as shown in Lemma 2. Baron (2001) refers to such profit-driven self-regulation as "strategic corporate social responsibility," in contrast to corporate social responsibility that is motivated altruistically.

Recall the notation $a=\theta_{H}-\theta_{L}$, and denote by $a_{0}$ the initial gap between the states. We consider self-regulation as a voluntary reduction in $\theta_{H}$ on the part of the firm, cutting $a$ from $a_{0}$ to $a_{1}$. That is, the firm's voluntary action reduces the severity of the DM's optimal policy in the high state of the world. Thus, if the firm reduces $\theta_{H}$ from $\theta_{L}+a_{0}$ to $\theta_{L}+a_{1}$ and if this induces the SIG to eschew lobbying, then the DM sets the average policy, i.e., $p=\theta_{L}+a_{1} / 2$, and the firm's payoff is $F^{S R}=-\beta\left(\theta_{L}+\right.$ $\left.a_{1} / 2\right)^{2}=-\beta\left(\theta_{L}^{2}+a_{1} \theta_{L}+a_{1}^{2} / 4\right) .{ }^{35}$ If the firm took no action and if the SIG revealed the true state through its lobbying decisions, then the firm's expected payoff would be $F^{0}=-\beta\left(\theta_{H}^{2}+\theta_{L}^{2}\right) / 2=-\beta\left(\theta_{L}^{2}+a_{0} \theta_{L}+a_{0}^{2} / 2\right)$. The net benefit to the firm is $\Delta^{S R}\left(a_{1}\right)=F^{S R}-F^{0}=\beta\left(a_{0}-a_{1}\right) \theta_{L}+\beta\left(2 a_{0}^{2}-\right.$ $\left.a_{1}^{2}\right) / 4>0$.

35. We could allow the firm to reduce both $\theta_{H}$ and $\theta_{L}$, and as long as the former is reduced more than the latter, all our results in this section still would go through. 
Given that the payoff function for the firm is $F=-\beta p^{2}$, how should we represent the cost of achieving $a$ ? If the firm were forced to comply with a policy of $p=\theta_{H}$, the cost difference between $a_{0}$ and $a_{1}$ would be $k\left(a_{1}\right)=-\beta\left(\theta_{L}+a_{1}\right)^{2}-\left(-\beta\left(\theta_{L}+a_{0}\right)^{2}\right)=\beta\left(2 \theta_{L}+a_{0}+a_{1}\right)\left(a_{0}-a_{1}\right)$. In order to be consistent with this payoff function, we will assume that the cost to the firm of achieving such a reduction is $k\left(a_{1}\right)=\beta\left(2 \theta_{L}+a_{0}+\right.$ $\left.a_{1}\right)\left(a_{0}-a_{1}\right)$. Thus, we allow the firm no extra benefit from engaging in unmandated reductions in $\theta_{H}{ }^{36}$

Combining the benefits and the cost of voluntary action (assuming the action is sufficient to render the SIG's lobbying choice uninformative) gives a net increase in profits from voluntary action of

$$
V\left(a_{1}\right)=\Delta^{S R}\left(a_{1}\right)-k\left(a_{1}\right)=\frac{3}{4} \beta a_{1}^{2}-\frac{1}{2} \beta a_{0}^{2}-\beta \theta_{L}\left(a_{0}-a_{1}\right) .
$$

Recalling that $a_{1}<a_{0}$, it is easy to see that $V\left(a_{1}\right)$ is positive for $a_{1}$ sufficiently close to $a_{0}$. Since $\partial V / \partial a_{1}>0$, the firm prefers the largest $a_{1}$ (smallest amount of self-regulation) that is sufficient to induce the SIG never to lobby. Let $\bar{a}_{1}$ be the smallest value of $a_{1}$ the firm is willing to choose; this can be found by setting $V\left(\bar{a}_{1}\right)=0$. Thus, the firm is willing to self-regulate to any value of $a$ between $\bar{a}_{1}$ and $a_{0}$ if this will undermine the SIG's lobbying efforts. ${ }^{37}$

How does self-regulation affect the decisions of the SIG? Recall that conditions (2) and (3) define when the positive-biased SIG will find it worthwhile to lobby before the DM. An informative equilibrium exists if $l \in[\underline{l}, \bar{l}]$, in which case the SIG lobbies when the state is $\theta_{H}$ but not when the state is $\theta_{L}$. Self-regulation shifts the initial point to the left in $(a, l)$ space and, in the process, may cause the SIG to change its lobbying behavior. This is perhaps seen most easily by reference to Figure 1, in which the values of $a$ and $l$ that support an informative equilibrium lie between the curves $[$ and $l$. Figure 3 builds on Figure 1 but adds two shaded regions, one of which is adjacent to $\bar{l}$, while the other is adjacent to $l$. In each of these regions, the initial point $\left(a_{0}, l\right)$ is within the region where the SIG's lobbying efforts are informative, but the firm finds it profitable to self-regulate, resulting in a leftward move that causes the

36. It is not uncommon in the literature on voluntary environmental agreements for authors to assume that voluntary actions are less costly than mandated actions. The authors of these papers argue that voluntary actions allow firms greater flexibility in meeting environmental goals. We refrain from modeling this exogenous bias, which serves only to make voluntary actions more desirable. For a discussion of papers that adopt this exogenous cost bias in favor of voluntary actions, see Lyon and Maxwell (forthcoming).

37. Note that $\bar{a}_{1}=-\frac{2 \beta}{3} \theta_{L}+\frac{2 \beta}{3} \sqrt{\left(\theta_{L}^{2}+3 \theta_{L} a_{0}+3 a_{0}^{2} / 2\right)}$ and is thus a function of $a_{0}$. However, in what follows we suppress this dependence for notational simplicity. 


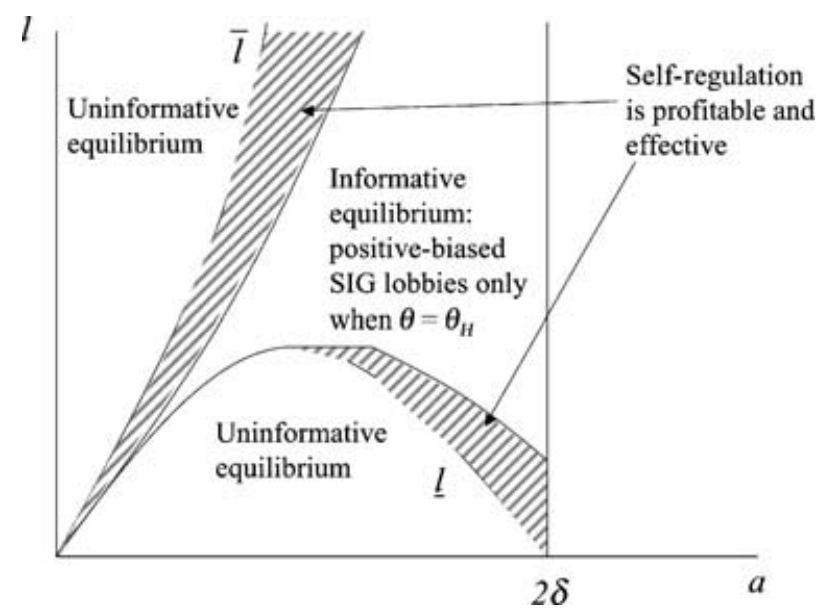

FIGURE 3. PROFITABILITY OF SELF-REGULATION

SIG to change behavior and eliminates the possibility of an informative equilibrium. We summarize these results in the following proposition.

Proposition 5: There exist two sets of parameters for which corporate self-regulation can alter interest group lobbying behavior profitably: (a) $a_{0}\left(2|\delta|+a_{0}\right)>l>a_{0}\left(2|\delta|-a_{0}\right)$ and $l>\left(a_{0}-\bar{a}_{1}\right)\left(2|\delta|+a_{0}-\bar{a}_{1}\right)$; or (b) $a_{0}\left(2|\delta|-a_{0}\right)<l<\left(a_{0}-\bar{a}_{1}\right)\left(2|\delta|-a_{0}+\bar{a}_{1}\right)$. For initial parameter values in either of these sets, self-regulation alters the incentives of the interest group, eliminating the possibility of an informative equilibrium.

Proof. Begin with case (a). We require two conditions. First, $a_{0}(2|\delta|+$ $\left.a_{0}\right)>l>a_{0}\left(2|\delta|-a_{0}\right)$ ensures that the initial pair $\left(a_{0}, l\right)$ is such that an informative equilibrium exists; that is, it ensures that $l \in(l, \bar{l})$. Second, $l>\left(a_{0}-\bar{a}_{1}\right)\left(2|\delta|+a_{0}-\bar{a}_{1}\right)$ ensures that after self-regulation $l>\bar{l}$, so that an informative equilibrium is not possible. Now turn to case (b). The condition $a_{0}\left(2|\delta|-a_{0}\right)<l$ ensures that at the initial parameter values, an informative equilibrium exists. The second condition, $l<$ $\left(a_{0}-\bar{a}_{1}\right)\left(2 \delta-a_{0}+\bar{a}_{1}\right)$, ensures that after self-regulation $l<\underline{l}$, in which case an informative equilibrium does not exist.

In this model, the key effect of self-regulation is to eliminate the possibility of an informative equilibrium. As we discussed in section 4 , the firm finds this profitable because reducing the flow of information insures the firm against adverse policy outcomes. This effect of self-regulation has not been noted previously in the literature. Prior work has shown that self-regulation can result in a lower level of environmental protection than would have emerged otherwise from the political process, but these papers were conducted in a setting 
where the decision-maker has complete information about the state of the world. ${ }^{38}$ Our results in this section show that self-regulation has additional implications when the decision-maker is not informed fully.

Although self-regulation reduces the flow of information to the decision-maker, it also reduces the severity of the worst-case scenario. Thus, the net impact of self-regulation on the decision-maker's payoff is more complicated than in the case of the bear hug. This is the subject of the following proposition.

Proposition 6: Self-regulation reduces the public decision-maker's expected payoff relative to the case of full information. However, the decisionmaker's expected payoff under self-regulation is greater than it would be under the bear hug.

Proof. Without self-regulation, the DM's expected payoff is simply $G^{0}=0$, since policy can be tailored precisely to the state of the world ex post. With self-regulation, the DM lacks information about the state and must set the average policy. Suppose that the firm's self-regulatory actions are observed by the DM. Then the DM sets $p=\theta_{L}+a_{1} / 2$, which is equal to the expected value of the state. Now the DM's expected payoff becomes

$$
E\left(G^{S R}\right)=-0.5\left(\theta_{L}+a_{1} / 2-\theta_{L}\right)^{2}-0.5\left(\theta_{L}+a_{1} / 2-\theta_{H}\right)^{2}=-a_{1}^{2} / 2<0 .
$$

Clearly $E\left(G^{S R}\right)<G^{0}$, and the DM is worse off as a result of the firm's self-regulatory action.

When the bear hug is used instead of self-regulation, the DM again sets the average policy, but relative to the initial value $a_{0}>a_{1}$. Thus, the DM's expected payoff under the bear hug is $E\left(G^{B H}\right)=-a_{0}^{2} / 2<$ $-a_{1}^{2} / 2$.

In our model, when the DM has full information about the state of the world, she can tailor policy precisely to the specifics of the situation before her, thereby reducing her loss function to zero. Self-regulation is undertaken by the firm only if it will render the SIG's lobbying uninformative. This deprives the DM of the information she desires, and as a result the DM is worse off. However, given that the firm undertakes an ex-ante strategy that renders lobbying uninformative, the DM obtains higher utility from self-regulation than from the bear hug. ${ }^{39}$ Nevertheless, although self-regulation reduces the severity of the high

38. For an introduction to the work on this subject, see Lyon and Maxwell (forthcoming).

39. We do not compare formally the DM's expected payoff in the astroturf equilibrium with that obtained under the bear hug or self-regulation. This is because the astroturf strategy is applicable only when the firm already knows the state of the world, while the other two strategies are applicable only when the firm does not know the state. 
state, it never compensates entirely for the loss of information caused by the decision to self-regulate.

\section{Multiple Interest Groups}

To this point, we have concentrated on cases involving only a single interest group. In this section, we discuss how our results may be extended to cases with multiple interest groups. We follow the typology used by Grossman and Helpman (2001) to classify the structure of multiple SIG situations: (1) Like bias arises when all groups share the same direction of bias but with different intensity; (2) Opposite bias arises when different groups are biased in opposite directions; and (3) Unknown bias arises when the groups receive imperfect signals regarding the state of the world. The first two cases, in contrast to the third, assume that both SIGs have perfect information regarding the state of the world at the time they lobby the DM. We consider these in turn, focusing on the case of two SIGs for simplicity.

\subsection{LIKE BIAS}

We will label the two SIGs radical and moderate, with the former possessing a larger value of $\delta$. We assume the moderate group, as in earlier sections, has a bias that satisfies conditions (1) through (3). The more radical group may meet these conditions but also could be so biased that it always lobbies and always claims that the state is high. This latter possibility may arise even if lobbying is costly, if the radical group's bias $(\delta)$ is high enough and the DM's off-equilibrium belief is that the state is low if the group fails to lobby. If the firm prefers a policy set at the average level, then it prefers to mute (render uninformative the group's lobbying actions) the moderate group, since the radical group lacks credibility anyway. This can be accomplished by bear hugging the moderate group exante, if that group's bias is great enough that it always will claim the state is high when lobbying is costless. (Alternatively, similar results can be achieved through astroturfing ex post, if the group has a negative bias.) Thus, this case differs little from the single SIG case analyzed previously.

Alternatively, if the radical SIG's bias is not too great, then the $\mathrm{DM}$ also could rely on it to provide reliable information through costly lobbying. In this case, bear hugging (or astroturfing) the moderate SIG will not be sufficient to affect the DM's decision. Instead, the firm must subsidize both SIGs. Again, however, this case differs only trivially from the case of a single SIG. ${ }^{40}$

40. Equilibria in all models with incomplete information depend critically on the beliefs held by the players. In our model, the actions of the firm depend on how the 
Overall, we conclude that the addition of a second SIG with like bias to that of the first SIG is unlikely to generate much additional insight. However, it is worth noting that if all groups must be subsidized, then the cost of any kind of subsidy strategy rises with the number of SIGs. This is not true of the self-regulation strategy, however. A single voluntary improvement affects all SIGs at once. If the firm undertakes enough voluntary action to preempt the involvement of the most extreme group, then all other groups will be preempted as well. Thus, we hypothesize that self-regulation is likely to outperform subsidy strategies as the number of SIGs grows. ${ }^{41}$

\subsection{OPposite BIAS}

When the two SIGs are biased in opposite directions, matters become more interesting. At least two types of equilibria are possible: (1) the DM ignores one SIG and simply relies on the other; and (2) each SIG lobbies in one state of the world, and the DM relies on both. In particular, an equilibrium of the second type may exist in which the SIG with positive bias lobbies in the high state, while the SIG with negative bias lobbies in the low state (see Grossman and Helpman, 2001, ch. 5 for details).

Case 1 is similar to the case of like bias. If the firm successfully renders uninformative the "active" SIG, either through the bear hug or through astroturf, then the inactive SIG may find it worthwhile to lobby, and the DM will find it worthwhile to pay attention to it. Thus, the firm needs to deal with both of the SIGs. Alternatively, the firm may use self-regulation to influence both SIGs at once.

Case 2 is somewhat more complex. On one hand, if the lobbying activities of one group are rendered ineffective, then the initial equilibrium is destroyed. However, there is an alternative equilibrium (Case 1) in which the DM pays attention to only one of the SIGs, and this becomes the only equilibrium if one SIG is silenced. Hence, the firm again must undermine the credibility of both groups, if it wishes to be successful. On the other hand, if the firm knows the state of the world, it might choose to engage in astroturf lobbying when the state is high, thereby inducing the negatively biased SIG to lobby at the same time that the positively biased SIG lobbies. The effectiveness of this strategy

DM chooses to interpret the lobbying actions of the SIGs. For example, suppose the DM held the belief that the state is high if both SIGs lobby and is low if neither firm lobbies, and he views any other outcome as uninformative. Then the firm would achieve the average policy by muting only one SIG.

41. This is likely to be the case particularly if the bias of the most radical group does not change as the number of groups grows. Otherwise, if the bias of the most radical group grows along with the number of groups, then the cost of self-regulation will grow as well, and the cost comparison becomes more difficult. 
will depend on the DM's beliefs in this out-of-equilibrium event. If, as seems reasonable, the DM sets the average policy when both SIGs lobby, then astroturf may be profitable in exactly the same way as in section 3 .

The general point is that the basic structure of our analysis appears to remain valid in the presence of multiple SIGs, as long as those SIGs all possess full information regarding the state of the world. The main change from adding multiple groups is that self-regulation may become relatively more attractive as the number of SIGs rises.

\subsection{UNKNOWN BIAS}

As before, one group is assumed to be radical and to be willing to lobby in both states of the world. However, the DM is assumed to be unable to distinguish one group from the other and hence only can make use of information regarding the number of firms that lobby. Lohmann (1993) analyzes this setting in the context of $N>2$ groups, but Grossman and Helpman (2001) show that her main insights can be derived in a model with just two groups. Consider the case of two groups with like biases. Lohmann emphasizes the case in which the more radical SIG always lobbies, regardless of the state. The DM does not know which group is the more biased but still can use the extent of lobbying as a noisy signal regarding the state of the world. For example, the DM may conclude that the state is high if two SIGs lobby and is low if only one does. ${ }^{42}$ If the firm can identify the more moderate SIG, then it can subsidize the moderate group, just as in the case of known bias. If this is not possible, then the firm must subsidize both groups.

Now consider the case of opposite bias. Suppose that the SIG with positive bias is the more radical one, and it plays the role of a pure advocate; that is, it always lobbies and claims the state is high. The more moderate SIG only lobbies when the state is low. Thus, the appearance of one SIG indicates that the state is high, while the appearance of two groups indicates the state is low; thus, the DM sets a low level of policy when both groups lobby but a high level when only one group lobbies. Once again, if the firm subsidizes the moderate group, then that group always (or never) will lobby, and the DM must set policy without gaining any information from the SIGs. If the firm cannot determine which group is which, then it must subsidize both.

42. A failure to lobby by both firms is off-equilibrium path behavior. Grossman and Helpman (2001, p. 154) identify beliefs for the DM under which it infers the state is low when neither firm lobbies. 


\section{CONCLUSIONS}

In this paper, we have developed a model to explore how a firm may influence the lobbying behavior of special interest groups when the firm's own lobbying efforts lack credibility with decision-makers. We built on the framework presented by Potters and van Winden (1992), in which costly lobbying may convey unverifiable information to a public decision-maker. The basic idea of this framework is that when lobbying is costly, an interest group's decision to lobby can provide credible information about the underlying state of the world. We have shown that firms may have both the incentive and the ability to undermine this information transmission process, reducing the public decision-maker's payoff in the process.

We considered three corporate nonmarket strategies: (1) astroturf, in which a firm that knows the state of the world subsidizes the lobbying activities of a group with similar views; (2) the bear hug, in which a firm that does not know the state of the world pays an interest group to alter its lobbying strategy; and (3) self-regulation, in which a firm that does not know the state of the world voluntarily limits the potential social harms from its activities. All of these strategies reduce the informativeness of lobbying, which can be profitable for the firm.

In many situations, the firm is likely to know the true state of the world already, especially if that state depends on characteristics of the firm's technology or management processes. For example, the state of the world might be the level of health risk associated with the operation of a particular plant, which depends upon corporate decisions regarding technology and management. In such settings, astroturf lobbying can be used by the firm, which covertly subsidizes the lobbying activity of an interest group with similar preferences in states of the world where the interest group would not lobby otherwise. For example, the group might represent local business organizations that stand to benefit if the firm builds a new plant in the area. We model this strategy as a form of costly state falsification. We show that the decision-maker has incentives to audit the relationship between the firm and the interest group for evidence of astroturf lobbying and to identify conditions under which astroturf lobbying nevertheless takes place in equilibrium. Our model shows that a law requiring the reporting of astroturf lobbying expenditures would render the strategy ineffective and that this would be desirable for the public decision-maker.

Requiring the reporting of astroturf lobbying expenditures is worthwhile but is not a panacea. We examine two alternative corporate strategies that also can reduce the informativeness of lobbying, even when their use is common knowledge to all players. These strategies 
differ from astroturf lobbying in that they can be used only by the firm before it learns the true state of the world. This is likely particularly in situations of true scientific uncertainty, such as currently exists regarding the future impacts of global warming. These alternative strategies can prevent special interest groups from informing the decision-maker about the true state after they learn its value.

The bear hug serves as a signal-jamming device that prevents the interest group from signaling the intensity of its views. Since the firm's costs are increasing and convex in policy stringency, the firm gains if the public decision-maker sets policy based on expected or average social harm rather than tailoring policy to actual harm ex post. The bear hug can be accomplished most cheaply by paying the interest group never to lobby. If this is unpalatable politically always for the interest group, however, the firm may pay the interest group to lobby, which also undermines the group's ability to convey information. One might expect that the group would be unwilling to accept a subsidy that reduces the credibility of its statements. Nevertheless, we show that if lobbying is costly enough, then it is incentive compatible for the group to accept the firm's embrace. It is important to note that this strategy may not be dynamically consistent for the firm: even though it raises expected profits exante, it is unprofitable ex post in some states of the world. Hence, the firm may have incentives to renegotiate the bear hug contract, a possibility that limits the circumstances in which this strategy can be used.

The third strategy we study is self-regulation, namely, voluntary actions to reduce the social harm that occurs in adverse states of the world. Such voluntary actions can change the lobbying incentives of interest groups and may render them uninformative, which is profitable for the firm in the same way as is the bear hug. This aspect of selfregulation has not been recognized previously in the literature. While self-regulation makes the decision-maker worse off, relative to the fullinformation outcome, we show that it is less harmful to the decisionmaker than is the bear hug strategy, which does not mitigate the severity of the worst-case scenario.

Our analysis focuses on the case of a single interest group but appears to be robust to the incorporation of multiple groups. The most interesting possibility that arises with multiple groups is that selfregulation becomes relatively more attractive, since a single investment in self-regulation can mute all groups at once, while the cost of a strategy based on subsidies rises linearly with the number of groups.

Under all three of the strategies we consider, the public decisionmaker is made worse off. The reason is that when the decision-maker is informed fully, she can tailor policy precisely ex post to the particular 
state of the world. All three of the strategies we study here are designed to stem the flow of information, and while this increases profits it simultaneously reduces the decision-maker's expected payoff.

\section{REFERENCES}

Baron, D.P., 2001, "Private Politics, Corporate Social Responsibility, and Integrated Strategy," Journal of Economics and Management Strategy, 10, 7-46.

Beckenstein, A.R., B. Webb, F.J. Long and B.L. Marcus, 1994, "Chlorine and the Paper Industry," in A.R. Beckenstein, F.J. Long, M.B. Arnold and T.N. Gladwin, eds., Stakeholder Negotiations: Exercises in Sustainable Development, Chicago, IL: McGraw Hill/Irwin, 120145 .

Becker, G.S., 1983, “A Theory of Competition among Pressure Groups for Political Influence," Quarterly Journal of Economics, 98, 371-400.

Craig, T., 2002, "Astroturf Lobbying: Community Leaders Decry Lobby Firm's Fax," Baltimore Sun, March 9, 2002, 1A.

Crawford, V. and J. Sobel, 1982, "Strategic Information Transmission," Econometrica, 50, 1431-1451.

Crocker, K.J. and S. Tennyson, 1999, "Costly State Falsification or Verification? Theory and Evidence from Bodily Injury Liability Claims," in G. Dionne and C. LabergeNadeau, eds., Automobile Insurance: Road Safety, New Drivers, Risks, Insurance Fraud, and Regulation, Boston, MA: Kluwer Academic Press, 74-89.

de Figueiredo, R.J.P., Jr., P.T. Spiller and S. Urbiztondo, 1999, “An Informational Perspective on Administrative Procedures," Journal of Law, Economics and Organization, 15, $283-305$.

DeSimone, L.D. and F. Popoff, 2000, Eco-Efficiency: The Business Link to Sustainable Development, Cambridge, MA: MIT Press.

Fudenberg, D. and J. Tirole, 1986, "A 'Signal-Jamming' Theory of Predation," RAND Journal of Economcis, 17, 366-376.

Greer, M.L. and A.K. Harding, 1993, "The Health Impact of Hazardous Waste Sites on Minority Communities: Implications for Public Health and Environmental Health Professionals," Journal of Environmental Health, 55(77), 6-9.

Grossman, G.M. and E. Helpman, 2001, Special Interest Politics, Cambridge, MA: MIT Press.

Huberty, R.M., 2003, "The Art of the Shakedown," Capital Research Center, May 23, 2003, http://www.capitalresearch.org/news/news.asp?ID=126, Accessed 1 September 2002.

Kollman, K., 1998, Outside Lobbying: Public Opinion and Interest Group Strategies, Princeton, NJ: Princeton University Press.

Krishna, V. and J. Morgan, 2001, “A Theory of Expertise," Quarterly Journal of Economics, $116,747-775$.

Lohmann, S., 1993, “A Signaling Model of Informative and Manipulative Political Action," American Political Science Review, 87, 319-333.

Lupia, A. and M.D. McCubbins, 1994, "Learning from Oversight: Fire Alarms and Police Patrols Reconstructed," Journal of Law, Economics and Organization, 10, 96-125.

Lyon, T.P. and J.W. Maxwell, Forthcoming, Corporate Environmentalism and Public Policy. Cambridge, UK: Cambridge University Press.

Maxwell, J.W., T.P. Lyon and S.C. Hackett, 2000, "Self-Regulation and Social Welfare: The Political Economy of Corporate Environmentalism," Journal of Law and Economics, 43, 583-617.

Milgrom, P. and J. Roberts, 1986, "Relying on the Information of Interested Parties," RAND Journal of Economics, 17, 18-32. 
Olson, M., 1965, The Logic of Collective Action, Cambridge, MA: Harvard University Press. Peltzman, S., 1976, "Toward a More General Theory of Regulation," Journal of Law and Economics, 19, 211-248.

Potters, J. and F. van Winden, 1992, "Lobbying and Asymmetric Information," Public Choice, 74, 269-292.

Sanchez, S., 1996, "How the West Is Won: Astroturf Lobbying and the 'Wise Use' Movement," American Prospect, 25, 37-42.

Stauber, J. and S. Rampton, 1995, Toxic Sludge Is Good for You: Lies, Damn Lies, and the Public Relations Industry, Monroe, ME: Common Courage Press.

Stigler, G.J., 1971, "The Economic Theory of Regulation," Bell Journal of Economics and Management Science, 2, 1-21.

Taylor, D., 1992, “The Environmental Justice Movement,” EPA Journal, 18(1), 24-36. 